\title{
Potential role of insulin receptor isoforms and IGF receptors in plaque instability of human and experimental atherosclerosis
}

\author{
Nuria Beneit ${ }^{1,2,3}$, José Luis Martín-Venturaa, ${ }^{4,5}$, Carlota Rubio-Longás ${ }^{1,2,3}$, Óscar Escribano 1,2,3, \\ Gema García-Gómez ${ }^{1,2,3}$, Silvia Fernández ${ }^{1,2,3}$, Giorgio Sesti ${ }^{6}$, Marta Letizia Hribal' ${ }^{6}$, Jesús Egido ${ }^{3,4,5}$, \\ Almudena Gómez-Hernández ${ }^{1,23^{*} \dagger}$ and Manuel Benito ${ }^{1,2,3 \dagger}$
}

\begin{abstract}
Background: Clinical complications associated with atherosclerotic plaques arise from luminal obstruction due to plaque growth or destabilization leading to rupture. We previously demonstrated that overexpression of insulin receptor isoform A (IRA) and insulin-like growth factor-l receptor (IGF-IR) confers a proliferative and migratory advantage to vascular smooth muscle cells (VSMCs) promoting plaque growth in early stages of atherosclerosis. However, the role of insulin receptor (IR) isoforms, IGF-IR or insulin-like growth factor-II receptor (IGF-IIR) in VSMCs apoptosis during advanced atherosclerosis remains unclear.

Methods: We evaluated IR isoforms expression in human carotid atherosclerotic plaques by consecutive immunoprecipitations of insulin receptor isoform B (IRB) and IRA. Western blot analysis was performed to measure IGF-IR, IGF$\| \mathrm{R}$, and a-smooth muscle actin (a-SMA) expression in human plaques. The expression of those proteins, as well as the presence of apoptotic cells, was analyzed by immunohistochemistry in experimental atherosclerosis using BATIRKO; $\mathrm{ApoE}^{-/}$mice, a model showing more aggravated vascular damage than ApoE ${ }^{-/-}$mice. Finally, apoptosis of VSMCs bearing IR (IRLoxP ${ }^{+/+}$VSMCs), or not (IR ${ }^{-/-}$VSMCs), expressing IRA (IRA VSMCs) or expressing IRB (IRB VSMCs), was assessed by Western blot against cleaved caspase 3 .

Results: We observed a significant decrease of IRA/IRB ratio in human complicated plaques as compared to noncomplicated regions. Moreover, complicated plaques showed a reduced IGF-IR expression, an increased IGF-IIR expression, and lower levels of a-SMA indicating a loss of VSMCs. In experimental atherosclerosis, we found a significant decrease of IRA with an increased IRB expression in aorta from 24-week-old BATIRKO; $\mathrm{ApoE}^{-/-}$mice. Furthermore, atherosclerotic plaques from BATIRKO; $\mathrm{ApoE}^{-/-}$mice had less VSMCs content and higher number of apoptotic cells. In vitro experiments showed that IGF-IR inhibition by picropodophyllin induced apoptosis in VSMCs. Apoptosis induced by thapsigargin was lower in $\mathrm{IR}^{-/-}$VSMCs expressing higher IGF-IR levels as compared to IRLoxP ${ }^{+/+}$VSMCs. Finally, IRB VSMCs are more prone to thapsigargin-induced apoptosis than IRA or IRLoxP ${ }^{+/+}$VSMCs.
\end{abstract}

Conclusions: In advanced human atherosclerosis, a reduction of IRA/IRB ratio, decreased IGF-IR expression, or increased IGF-IIR may contribute to VSMCs apoptosis, promoting plaque instability and increasing the risk of plaque rupture and its clinical consequences.

Keywords: Atherosclerosis, Insulin receptor isoforms, Insulin-like growth factor receptor, Vascular smooth muscle cells, Apoptosis

\footnotetext{
*Correspondence: algomezh@ucm.es

${ }^{\dagger}$ Almudena Gómez-Hernández and Manuel Benito are co-senior authors

${ }^{1}$ Biochemistry and Molecular Biology II Department, School

of Pharmacy, Complutense University of Madrid, Plaza Ramón y Cajal s/n,

28040 Madrid, Spain

Full list of author information is available at the end of the article
} 


\section{Background}

Atherosclerosis is a chronic disease affecting large arteries that involves the formation of plaques containing vascular and inflammatory cells, lipids and extracellular matrix [1]. Its clinical complications arise from luminal obstruction due to plaque growth leading to vessel stenosis, and/or formation of unstable plaques that acutely rupture leading to an occlusive thrombus formation [2]. Vascular smooth muscle cells (VSMCs) play a main role in this process as they contribute to plaque growth in early stages, but favor plaque stability in advanced stages of atherogenesis [3].

The insulin and insulin-like growth factors (IGFs) signaling is mediated by hormone interaction with the insulin receptor (IR) and the IGF-I receptor (IGF-IR), which are members of subclass II tyrosine kinase receptor superfamily $[4,5]$. In mammals, alternative splicing of the IR gene gives rise to two isoforms: IRA and IRB [6]. Indeed, IRB has an additional 12-amino acid sequence encoded by the exon 11. Although both isoforms have similar affinity for insulin, IRA exhibits a higher affinity for IGFs, especially for IGF-II [7]. Thus, IRB is preferentially associated with metabolic and differentiating signals, whereas IRA mainly favors cell growth, proliferation and survival [8]. In addition to IR and IGF-IR, IGF-II binds IGF-II receptor (IGF-IIR) with high affinity. IGF-IIR is a type I transmembrane glycoprotein that also have high affinity for mannose-6-phosphate, and can therefore bind lysosomal enzymes and other growth factors and cytokines [9]. It plays a well-documented role in the intracellular transport of lysosomal enzymes and in clearance of IGF-II from the circulation. However, although IGF-IIR contains neither tyrosine kinase activity nor an autophosphorylation site, it does link to G-proteins providing a mechanism for signal transduction that may be involved in cell behavior regulation $[10,11]$.

In early atherosclerotic lesions, IGFs contribute to plaque growth by promoting VSMCs proliferation and migration [12]. In this regard, we previously demonstrated that overexpression of IGF-IR or IRA isoform during early atherosclerosis confers a proliferative and migratory advantage to VSMCs favoring atherosclerotic progression $[13,14]$. In advanced stages, the imbalance between cell death and survival may substantially affect the cellularity and integrity of atherosclerotic lesions contributing to plaque instability. Unstable plaques that are prone to rupture have a thin fibrous cap with a decreased number of VSMCs and a dense infiltration of inflammatory cells $[15,16]$, as well as an increased apoptosis of VSMCs and macrophages [17]. IGF-I, through IGFIR, has been reported to prevent atherosclerotic plaque instability by its mitogenic and antiapoptotic effects on VSMCs [18-20]. However, the role of IR isoforms or
IGF-IIR in VSMCs apoptosis and thereby in plaque instability remains unknown. In the present study, we analyzed the expression of IR isoforms, IGF-IR and IGF-IIR, as well as VSMCs content in human carotid atherosclerotic plaques and in experimental models of atherosclerosis. Finally, we assessed the contribution of IR isoforms and IGF-IR to the apoptosis of murine aortic VSMCs lines.

\section{Methods \\ Patients}

Ten atherosclerotic plaques from patients undergoing carotid endarterectomy at IIS-Fundación Jiménez Díaz (Table 1) were dissected separating the stenosing complicated plaque $(\mathrm{CP})$ from the non-complicated (NCP) fibrous adjacent area. The CP was defined as the lesion, usually localized at the origin of the internal carotid artery responsible for the surgery. The $\mathrm{CP}$ contained an important proportion of inflammatory cells (Stary stages $\mathrm{V}-\mathrm{VI}$ ), whereas the NCP adjacent areas were mainly composed of VSMCs and lipid deposits (Stary stage III). Masson's trichrome stain of representative NCP and CP samples are shown. The study was approved by the hospital's ethics committee (IIS-Fundación Jiménez Díaz) with the reference number (PI1442016) according to the institutional and the Good Clinical Practice guidelines, which was performed in accordance with the Declaration of Helsinki. All participants gave written informed consent.

\section{Experimental models}

Male mice were maintained on a 12-h light-dark cycle and $23{ }^{\circ} \mathrm{C}$ room temperature. All animals used are under C57BL/6 genetic background [21]. Generation of brown adipose tissue-specific insulin receptor knockout (BATIRKO); $\mathrm{ApoE}^{-/-}$mice by crossing female $\mathrm{ApoE}^{-/-}$mice with male BATIRKO mice was previously described [21]. Six week-old male Control mice, $\mathrm{ApoE}^{-/-}$mice and BATIRKO; ApoE ${ }^{-1-}$ mice were fed on a standard diet (3\% kcal from fat) for 62 weeks or a Western type diet ( $21 \% \mathrm{kcal}$ from fat) for 18 weeks, and sacrificed at 24 weeks or 15 months of age, respectively. Anesthetized

\section{Table 1 Clinical characteristics of patients bearing carotid atherosclerosis}

\begin{tabular}{lc}
\hline Variable & Patients $(\mathbf{n}=\mathbf{1 0})$ \\
\hline Age, years & $69(57-78)$ \\
Gender (male/female), \% & $100 / 0$ \\
Diabetes mellitus, \% & 50 \\
Hypertension, \% & 60 \\
Dyslipidemia, \% & 50 \\
Coronary artery disease, \% & 30 \\
Current smoking, \% & 50 \\
\hline
\end{tabular}


mice (Avertin, $250 \mathrm{mg} / \mathrm{kg}$, ip) were saline-perfused. The aortic root was embedded in Tissue-Tek ${ }^{\circledR}$ optimum cutting temperature (OCT) Compound and frozen for histological analysis, and the thoracic aorta was frozen for RNA extraction. All animal experimentation described in this manuscript was conducted according with accepted standards of human animal care, as approved by the institutional committee of Complutense University of Madrid (reference number: ES280790000086). All animal procedures have been performed according to the guidelines from Directive 2010/63/EU of the European Parliament and the National Institutes of Health (NIH) on the protection of animals used for scientific purposes.

\section{Cell cultures}

Generation of immortalized IRLoxP $\mathrm{P}^{+/+}, \mathrm{IR}^{-/-}$, IRA and IRB VSMCs lines was previously described [13]. Briefly, primary VSMCs were obtained from thoracic aorta arteries of 3 male 8-week-old IRLoxP ${ }^{+/+}$mice. Anesthetized mice (Avertin, $250 \mathrm{mg} / \mathrm{kg}$, ip) were saline perfused and thoracic aorta arteries were submitted to collagenase dispersion and primary culture. Then, primary culture of IRLoxP $\mathrm{P}^{+/+}$VSMCs were immortalized by transfection with pBabe retroviral vector encoding SV40 Large T antigen and selected with $1 \mu \mathrm{g} / \mathrm{mL}$ puromycin for 3 weeks. Immortalized IRLoxP $\mathrm{P}^{+/+}$VSMCs were infected with adenoviruses encoding Cre recombinase to obtain $\mathrm{IR}^{-1-}$ VSMCs. Finally, $\mathrm{IR}^{-l-}$ VSMCs were transfected with pBABE retroviral vector encoding the individual spliced isoforms of the human IR, IRA or IRB, and selected with $200 \mu \mathrm{g} / \mathrm{mL}$ hygromycin for 2 weeks to obtain IRA or IRB VSMCs respectively.

Cell lines were cultured to subconfluence $(70-80 \%)$ with $10 \%$ foetal bovine serum (FBS)-DMEM for in vitro experiments. Cells were serum and glucose starved for 4-5 $\mathrm{h}$ and then treated with IGF-I $(10 \mathrm{nmol} / \mathrm{L}$, Merck Millipore), IGF-II (10 nmol/L, Merck Millipore), the IGF-IR inhibitor picropodophyllin $(1 \mu \mathrm{mol} / \mathrm{L}$, PPP, Merck Millipore), and/or thapsigargin (0.1-100 nmol/L, Sigma-Aldrich).

\section{Histological analysis}

Paraffin-embedded human carotid atherosclerotic plaques were cross sectioned into $4 \mu \mathrm{m}$ thick pieces, dewaxed, and rehydrated. Masson trichrome were performed following manufacturer's instructions and as previously described [22].

Aortic roots from experimental models were OCTembedded and sections of $7 \mu \mathrm{m}$ interval were used for immunohistochemical studies. IR, IGF-IR, IGF-IIR and cleaved poly ADP ribose polymerase (PARP) were detected by immunoperoxidase with rabbit anti-IR $\beta$ (sc711), anti-IGF-IR $\beta$ (sc-713) and anti-IGF-IIR (sc-25462) polyclonal antibodies and anti-Cleaved PARP (ab32064) monoclonal antibody. We also performed immunofluorescence against $\alpha$-SMA using anti-actin, $\alpha$-smooth muscle-Cy $3^{\mathrm{TM}}$ mouse monoclonal antibody (C6198, Sigma-Aldrich) followed by 4',6-diamidino-2-phenylindole (DAPI) staining to localize nuclei.

\section{Western blot analysis}

Western blot analyses were performed on protein extracts from human plaques and from in vitro experiments as previously described [22]. The antibodies used were anti-IR $\beta$, IGF-IR $\beta$ and IGF-IIR from Santa Cruz Biotechnology (Dallas, TX, USA); IRS-1 from Millipore (Billerica, MA, USA); p-IRS-1 (Ser307), p-AKT (Thr308), p-p42/44 MAPK (Thr202/Tyr204) and Cleaved Caspase-3 (Asp175) from Cell Signaling Technology (Danvers, MA, USA); anti- $\beta$-actin, $\alpha$-SMA and $\alpha$-tubulin from Sigma-Aldrich Corp. (St. Louis, MO, USA).

\section{Immunoprecipitation}

An amount of $150 \mu \mathrm{g}$ protein from human plaques was immunoprecipitated at $4{ }^{\circ} \mathrm{C}$ with IRB isoform antibody (provided by Dr. Sesti and Dr. Hribal). Supernatants were subsequently immunoprecipitated with IR $\beta$ antibody recognizing both IR isoforms. Thus, immune complexes from first (only IRB isoform) or second (only IRA isoform) immunoprecipitations were collected on protein A-agarose beads and submitted to SDS-PAGE. Finally, immunoblots were incubated with anti-IRB or anti-IR $\beta$ antibodies to analyze the expression of IRB and IRA, respectively. To study the association between IR isoforms and IGF-IR or insulin receptor substrate 1 (IRS-1), immunoblots were reincubated with anti-IGF-I $\beta$, IRS-1 or p-IRS (Ser307) antibodies.

\section{RNA extraction and real-time quantitative polymerase chain reaction}

Total RNA was isolated from aorta of experimental models using TRIzol reagent (Invitrogen, Carlsbad, CA) and quantified by absorbance at $260 \mathrm{~nm}$. One microgram of RNA was used to perform the reverse transcription with a High Capacity cDNA Archive kit (Applied Biosystems, Foster City, CA). Real-time quantitative PCR (qRT-PCR) was performed on an ABI Prism 7900 sequence detection PCR system (Applied Biosystems) according to the manufacturer's protocol, using the $\Delta \Delta \mathrm{Ct}$ method as previously described [23]. Thus, the amount of target, normalized to endogenous gene and relative to the control, is given by real-time quantitative (RQ) $=2^{-\Delta \Delta C t} ; \Delta \mathrm{Ct}$ (cycle threshold) $=\mathrm{Ct}$ (target gene) $-\mathrm{Ct}(\mathrm{GAPDH})$; $\Delta \Delta \mathrm{Ct}=\Delta \mathrm{Ct}$ for any sample $-\Delta \mathrm{Ct}$ for the control. Amplification of GAPDH was used in the same reaction of all samples as an internal control. 


\section{Annexin V-FITC and propidium iodide assays}

$10^{6}$ cells were seeded in $60 \mathrm{~mm}$-plates and the following day they were FBS deprived for $4 \mathrm{~h}$ and stimulated with IGF-I, IGF-II or PPP $1 \mathrm{~h}$-previous to stimulation with thapsigargin for $18 \mathrm{~h}$. After that, cells were counted and collected to perform apoptosis studies with Annexin V-FITC kit. Apoptotic cells are positively stained for Annexin V-FITC that binds to phosphatidylserine (PS) residues, but are negatively stained for propidium iodide (PI). Dead cells are positive for both, Annexin V-FITC and PI staining, whereas viable cells are negative for both Annexin V-FITC and PI. Finally, necrotic cells are positively stained for PI and negatively for Annexin V-FITC. For these experiments, a FACScalibur flow cytometer and Cell Quest Pro software (Becton-Dickinson) was used.

\section{Statistical analysis}

All values are expressed as mean \pm standard error of the mean (SEM). Differences between two groups were assessed using paired two-tailed $t$-tests for human samples and unpaired two-tailed $t$-tests for experimental models and in vitro experiments. Data involving more than two groups were analyzed using a one-way ANOVA followed by a Bonferroni test if differences were noted (GraphPad Prism 6.0). The null hypothesis was rejected when $\mathrm{p}<0.05$.

\section{Results}

Decrease of IRA/IRB ratio and IGF-IR, increase of IGF-IIR, and loss of VSMCs in complicated human atherosclerotic plaques

To assess the role of IR isoforms, IGF-IR and IGF-IIR in human advanced atherosclerosis, we used atherosclerotic plaques from patients undergoing carotid endarterectomy. Ten carotid endarterectomy samples were carefully dissected separating the stenosing complicated plaque (CP, Stary stages V-VI) from the non-complicated (NCP, Stary stages III) fibrous adjacent area. Histological analysis revealed that complicated plaques contained an intraplaque hemorrhage and/or a certain degree of calcification with a relatively important proportion of inflammatory cells. The adjacent non-complicated regions were composed of fibrous thickening with a variable content of VSMCs (Additional file 1: Figure S1).

Firstly, the expression of each IR isoform and its association with IGF-IR or IRS-1 were comparatively analyzed in complicated and non-complicated regions of human plaques by consecutive immunoprecipitations of IRB and IRA isoforms (Fig. 1). We observed a significant decrease of IRA expression, together with an increase of IRB, in complicated regions (Fig. 1b). We also found that the expression of IRA/IGF-IR hybrid receptors was significantly higher in complicated regions of plaques (Fig. 1c). Regarding IRS-1 association with IRA or IRB, no significant differences were found in complicated as compared to non-complicated regions of the plaques (Fig. 1d).

Nevertheless, IRA or IRB-associated IRS-1 showed an increased inhibitory Ser307 phosphorylation in complicated regions compared to non-complicated regions of plaques (Fig. 1e). Moreover, we observed a decreased insulin signaling in terms of Akt and p42/44 MAPK phosphorylation in complicated regions vs. non-complicated regions of atherosclerotic plaques (Additional file 2: Figure S2). To evaluate the expression of IGF-IR, we used the supernatants of the second immunoprecipitation in which this receptor would be as homodimers, since IR-associated IGF-IR was previously immunoprecipitated (Fig. 2a). We observed a reduced IGF-IR expression in complicated regions of the plaques. Conversely, the expression of IGF-IIR was significantly increased in complicated as compared to non-complicated regions of plaques (Fig. 2a).

In advanced atherosclerotic plaques, a loss of VSMCs as a result of their increased apoptosis may be key in plaque instability that seriously increases the risk of rupture. We therefore analyzed the content of VSMCs in human atherosclerotic plaques. Western blot analysis of $\alpha$-smooth muscle actin ( $\alpha$-SMA), a well-known marker of smooth muscle cells, showed a significant reduction of VSMCs number in complicated as compared to noncomplicated regions of plaques (Fig. 2b).

\section{Decrease of IRA/IRB ratio and less VSMCs content in experimental atherosclerotic models}

We wondered whether the findings obtained from human atherosclerotic plaques could also occur in experimental models of atherosclerosis. For this purpose, 24-week-old BATIRKO; $\mathrm{ApoE}^{-/-}$mice under a Western type diet were used to develop more advanced atherosclerotic lesions as compared to Control and $\mathrm{ApoE}^{-1-}$ mice. These mice showed higher vascular damage, characterized by a significant increase of stenosis, lesion area, lipid content and macrophage infiltration in aortic roots, than 24-weekold $\mathrm{ApoE}^{-/-}$mice [21]. In a second approach, Control, $\mathrm{ApoE}^{-/-}$and BATIRKO; ApoE ${ }^{-/-}$mice were fed on a standard diet and sacrificed at 15 months of age. Protein levels of IR in total area of aortic roots were very similar among the three groups of animals from the two experimental models (Fig. 3a and Additional file 3: Figure S3A). However, the receptor was significantly diminished in the media of aortic roots from $\mathrm{ApoE}^{-1-}$ and BATIRKO; $\mathrm{ApoE}^{-1-}$ mice in both 24-week-old and 15-month-old models. We observed by qRT-PCR that mRNA expression of IRA isoform was significantly decreased, whereas 


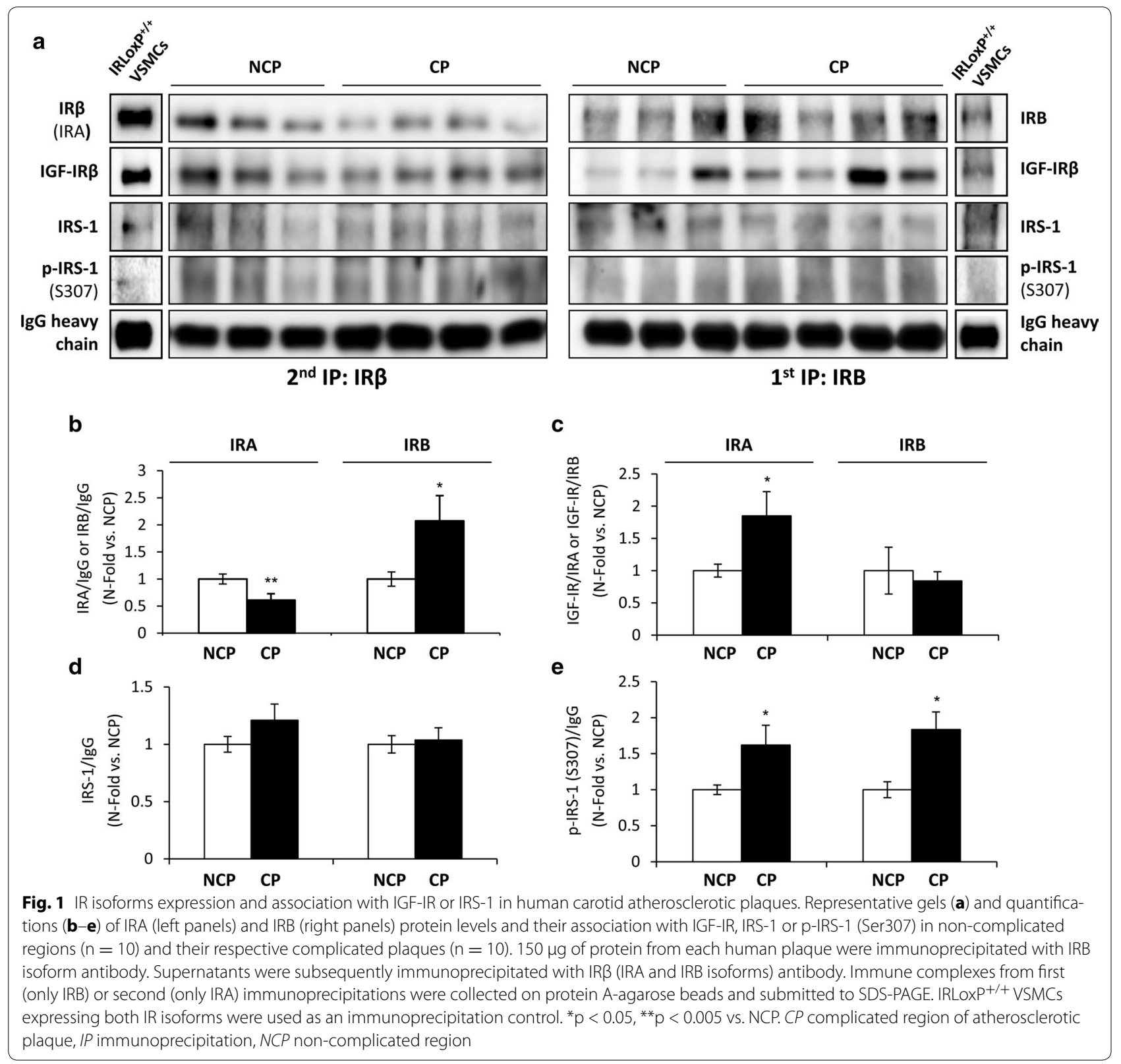

IRB was increased in aorta from 24-week-old BATIRKO; $\mathrm{ApoE}^{-1-}$ mice (Fig. 3b). These data are consistent with the reduced IRA/IRB ratio found in complicated human plaques (Fig. 1b). A significant increase of IGF-IR protein was observed in aortic roots from both 24-week-old and 15 month-old BATIRKO; ApoE ${ }^{-1-}$ mice in relation to their respective ApoE ${ }^{-1-}$ groups (Fig. $3 \mathrm{c}$ and Additional file 3: Figure S3B). Consistently, IGF-IR mRNA expression was significantly higher in aorta from 24-week-old BATIRKO; $\mathrm{ApoE}^{-1-}$ mice (Fig. 3d). IGF-IIR expression showed an increasing trend, although not significant, in aortic roots from 24-week-old mice BATIRKO; ApoE ${ }^{-/-}$ mice (Fig. 3e).

To study the VSMCs content in the atherosclerotic lesions of experimental models, we analyzed by immunohistochemistry the $\alpha$-SMA expression in aortic roots from the different groups of animals. A very significant reduction of $\alpha$-SMA was found in 24-week-old BATIRKO; $\mathrm{ApoE}^{-1-}$ mice as compared to the respective Control and $\mathrm{ApoE}^{-1-}$ groups (Fig. 4a). Moreover, atherosclerotic plaques from 15 month-old BATIRKO; $\mathrm{ApoE}^{-/-}$ mice also contained a significantly lower number of 

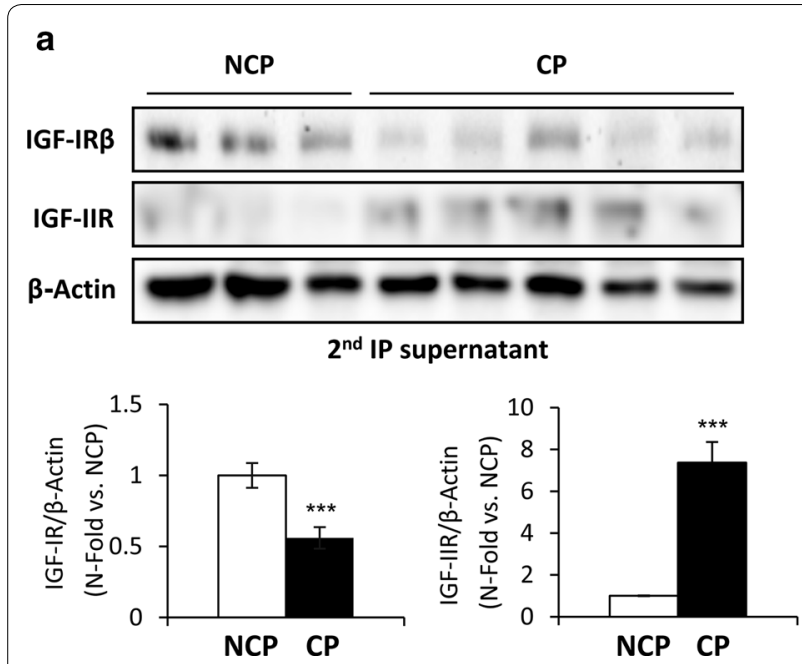

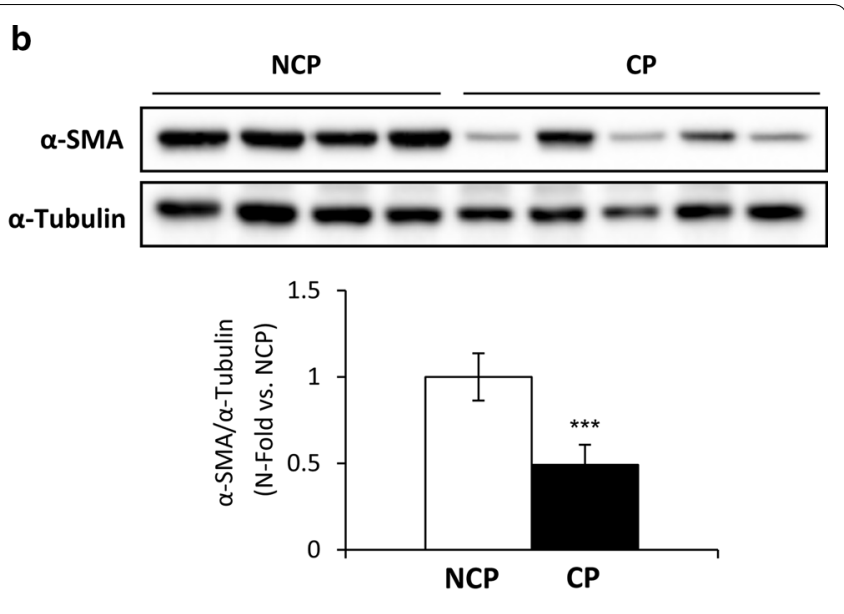

b

Fig. 2 IGF-IR and IGF-IIR expression, and VSMCs content in human carotid atherosclerotic plaques. a Representative gels and quantifications of IGF-IR and IGF-IIR protein levels in supernatants from serial immunoprecipitations (IRB and IRA) of non-complicated regions $(n=10)$ and their respective complicated plaques $(n=10)$. b Analysis of VSMCs content by Western blot against a-SMA in non-complicated regions $(n=10)$ and their respective complicated plaques $(n=10)$. ${ }^{* * *} \mathrm{p}<0.0005$ vs. NCP. CP complicated region of atherosclerotic plaque, IP immunoprecipitation, NCP non-complicated region

VSMCs than 15 month-old Control mice (Additional file 4: Figure S4A). An increased apoptosis is the major cause for the loss of VSMCs during atherogenesis [17]. We therefore evaluated the presence of apoptotic cells in aortic roots by immunostaining of the apoptosis marker cleaved poly ADP ribose polymerase (PARP). The amount of cleaved $\mathrm{PARP}^{+}$cells was markedly increased in aortic roots from both 24-week-old $\mathrm{ApoE}^{-1-}$ and BATIRKO;ApoE ${ }^{-1-}$ mice in relation to 24-week-old Control mice (Fig. 4b). Similarly, aortic roots from 15 monthold $\mathrm{ApoE}^{-1-}$ and BATIRKO; ApoE ${ }^{-1-}$ mice had higher number of apoptotic cells than 15 month-old Control mice. In addition, the presence of apoptotic cells was significantly higher in 15 month-old BATIRKO; $\mathrm{ApoE}^{-/-}$ mice as compared to $\mathrm{ApoE}^{-1-}$ group (Additional file 4: Figure S4B).

\section{Antiapoptotic effect of IGF-IR on VSMCs}

To assess the role of IR isoforms and IGF-IR in VSMCs apoptosis, four murine aortic VSMCs lines were used: bearing IR (IRLoxP $\left.\mathrm{P}^{+/+} \mathrm{VSMCs}\right)$, lacking IR $\left(\mathrm{IR}^{-/-}\right.$ VSMCs), expressing IRA isoform (IRA VSMCs) or alternatively expressing IRB isoform (IRB VSMCs). We previously demonstrated that IGF-IR is a main contributor to VSMC migration during early stages of atherosclerosis [14]. In the current work, we hypothesized that a decreased expression or activation of IGF-IR might promote apoptosis of VSMCs. To assure this, IRLoxP $\mathrm{P}^{+/+}$and $\mathrm{IR}^{-1-}$ VSMCs were treated with the highly specific inhibitor of IGF-IR tyrosine phosphorylation picropodophyllin
(PPP) for $24 \mathrm{~h}$. Western blot analysis of cleaved caspase 3 revealed that IGF-IR inhibition induced apoptosis in both cell lines (Fig. 5a). We also observed a significant increase of cleaved caspase 3 when cells were stimulated with IGF-I or IGF-II in the presence of PPP, this effect being greater with IGF-II stimulation (Fig. 5a). Afterwards, a dose-response curve of thapsigargin, an inhibitor of the endoplasmic reticulum (ER) $\mathrm{Ca}^{2+}$-ATPase inducing ER stress [24], was performed in IRLoxP ${ }^{+/+}$and $\mathrm{IR}^{-/-}$VSMCs. The expression of cleaved caspase 3 was found at a $100 \mathrm{nmol} / \mathrm{L}$ dose of thapsigargin in the two cell lines studied and this effect was significantly lower in $\mathrm{IR}^{-/-}$VSMCs (Fig. 5b). Additionally, pretreatment with IGF-I, but not with IGF-II, reduced thapsigargin-induced apoptosis in IRLoxP $\mathrm{P}^{+/+}$and $\mathrm{IR}^{-/-}$VSMCs measured by Western blot of active caspase 3 (Fig. 5c). In this sense, we also checked that IGF-I increased the percentage of viable cells and prevented from early and late apoptosis in IRLoxP $\mathrm{P}^{+/+}$and $\mathrm{IR}^{-/-}$VSMCs (Additional file 5: Figure S5). These results suggest that IGF-I through IGF-IR has an antiapoptotic effect on VSMCs that may favor plaque stability by preventing the loss of those cells in atherosclerotic plaques.

Based on the reduced IRA/IRB ratio observed in complicated human plaques and in advanced experimental atherosclerosis, we wondered whether IR isoforms could have a differential contribution to VSMCs apoptosis. For this purpose, we studied the apoptosis induced by thapsigargin in IRA and IRB VSMCs. Cells exclusively expressing IRB showed a significantly higher increase of 


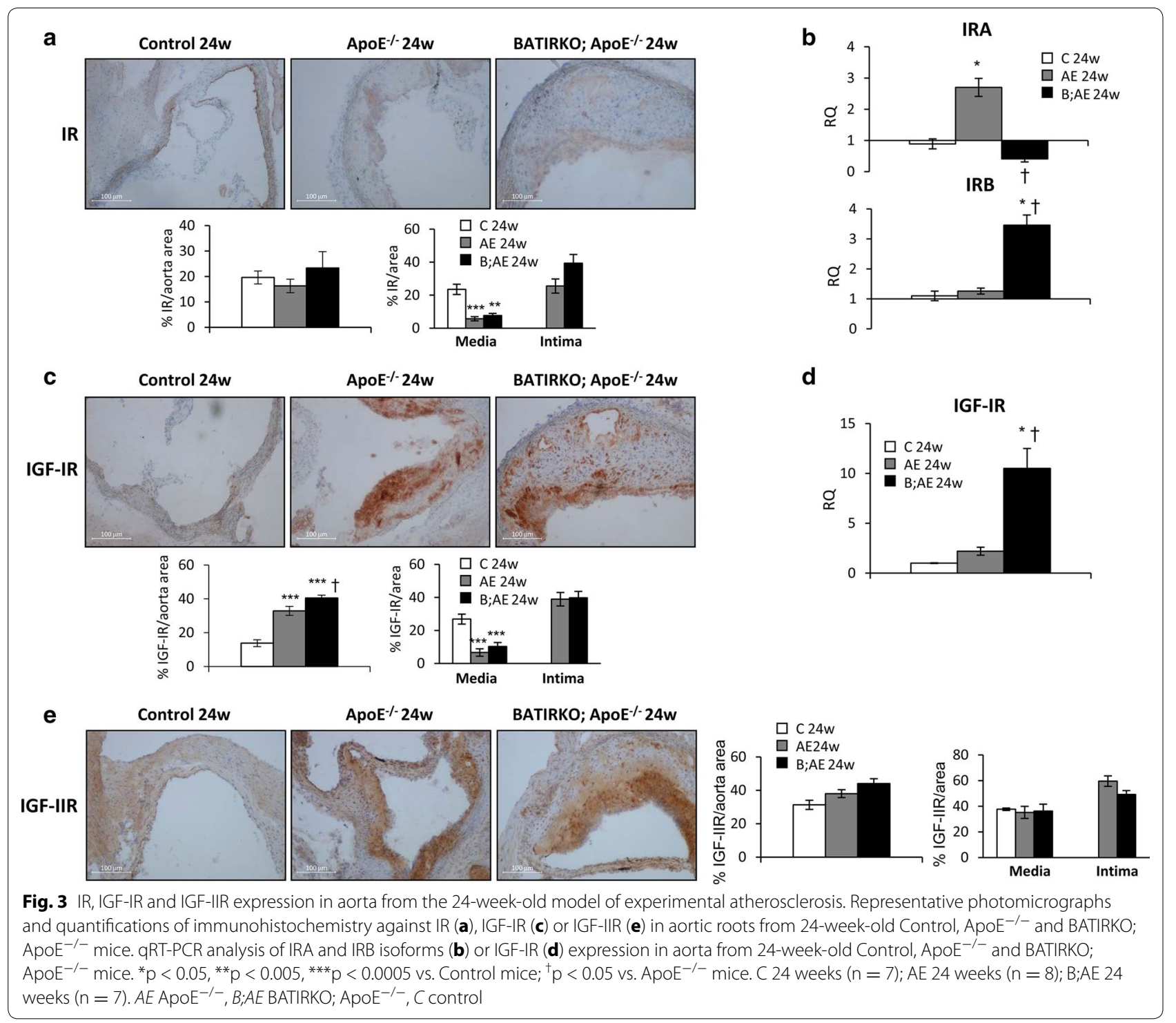

cleaved caspase 3 as compared to IRA VSMCs (Fig. 6a). Finally, IGF-IR inhibition by PPP enhanced the thapsigargin-induced apoptosis of IRB VSMCs in a significant way (Fig. 6b, c and Additional file 6: Figure S6). However, in IRLoxP $\mathrm{P}^{+/+}$VSMCs, expressing both IR isoforms, PPP caused a lower increase of cleaved caspase 3 levels (Fig. 6b, c and Additional file 6: Figure S6). These data indicate that, in addition to IGF-IR inhibition, decreased IRA/IRB ratio may contribute to VSMCs apoptosis and thereby to plaque instability (Fig. 7).

\section{Discussion}

In early stages of atherosclerosis, abnormal proliferation and migration of VSMCs is a major contributor to atherogenesis. By contrast, VSMCs in advanced lesions are generally regarded as having atheroprotective plaque-stabilizing properties [3]. Indeed, clinical studies have reported that atherosclerotic plaques with a relative decrease of VSMCs and a thin fibrous cap, as well as increased inflammatory cells, were less stable and more prone to rupture $[25,26]$. In this sense, it has been described that VSMCs present in human atherosclerotic lesions showed higher apoptosis than those derived from normal vessels [27].

The IR isoforms possess different functional features. Whereas IRB upregulation is associated with predominant metabolic insulin signaling, an increased expression of IRA is associated with decreased metabolic insulin signaling and increased IGF signaling, favoring cell growth, proliferation and survival [8]. We previously 


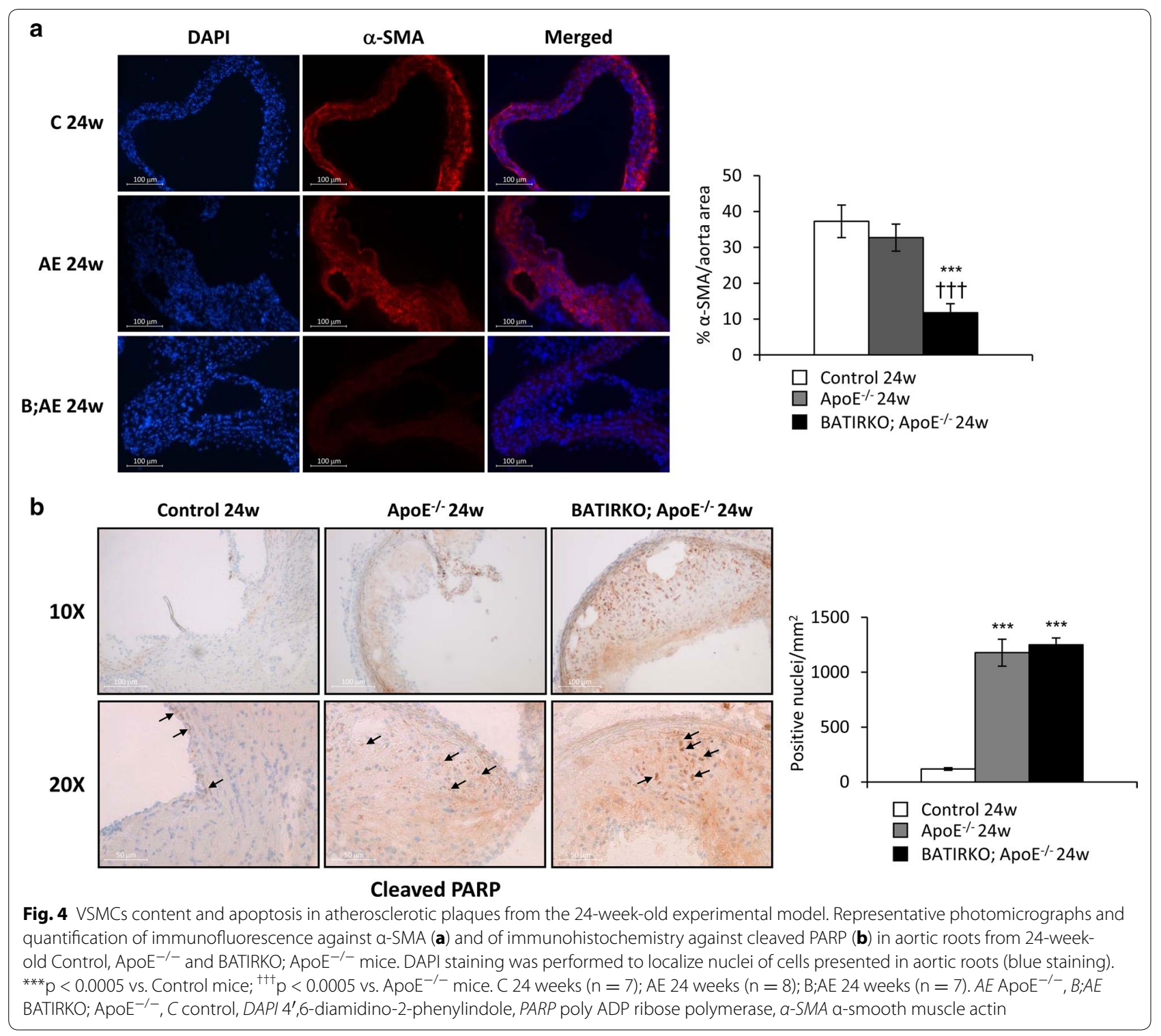

described that overexpression of IRA isoform favors VSMCs proliferation and migration contributing to atherosclerotic progression [13, 14]. However, to our knowledge, no data are available regarding the expression profile of IR isoforms in advanced atherosclerotic lesions and their role in VSMCs apoptosis. In the current paper, we have shown a decreased IRA/IRB ratio in complicated regions of human atherosclerotic plaques. Since IRA isoform binds IGF-II with higher affinity than IRB [7], its overexpression may promote proatherogenic effects of IGF-II in early stages of atherosclerotic process. Conversely, in more advanced stages, in which a local action of IGF-II prevents plaque instability by promoting the proliferation of intimal VSMCs [28], a reduced IRA/IRB ratio could favor the destabilization of atherosclerotic plaques. Although there were no significant changes on IRS-1 association with IR isoforms, its serine phosphorylation was increased as well as Akt and $\mathrm{p} 42 / 44$ MAPK phosphorylation were diminished in complicated regions of human plaques. The phosphorylation of IRS- 1 on serine residues is associated with insulin resistance induced by cytokines such as TNF- $\alpha$, since it inhibits IRS-1 tyrosine phosphorylation leading to impaired insulin signaling [29]. In addition, the increase of IRA/IGF-IR hybrid receptors in complicated regions might also be contributing to vascular insulin resistance 


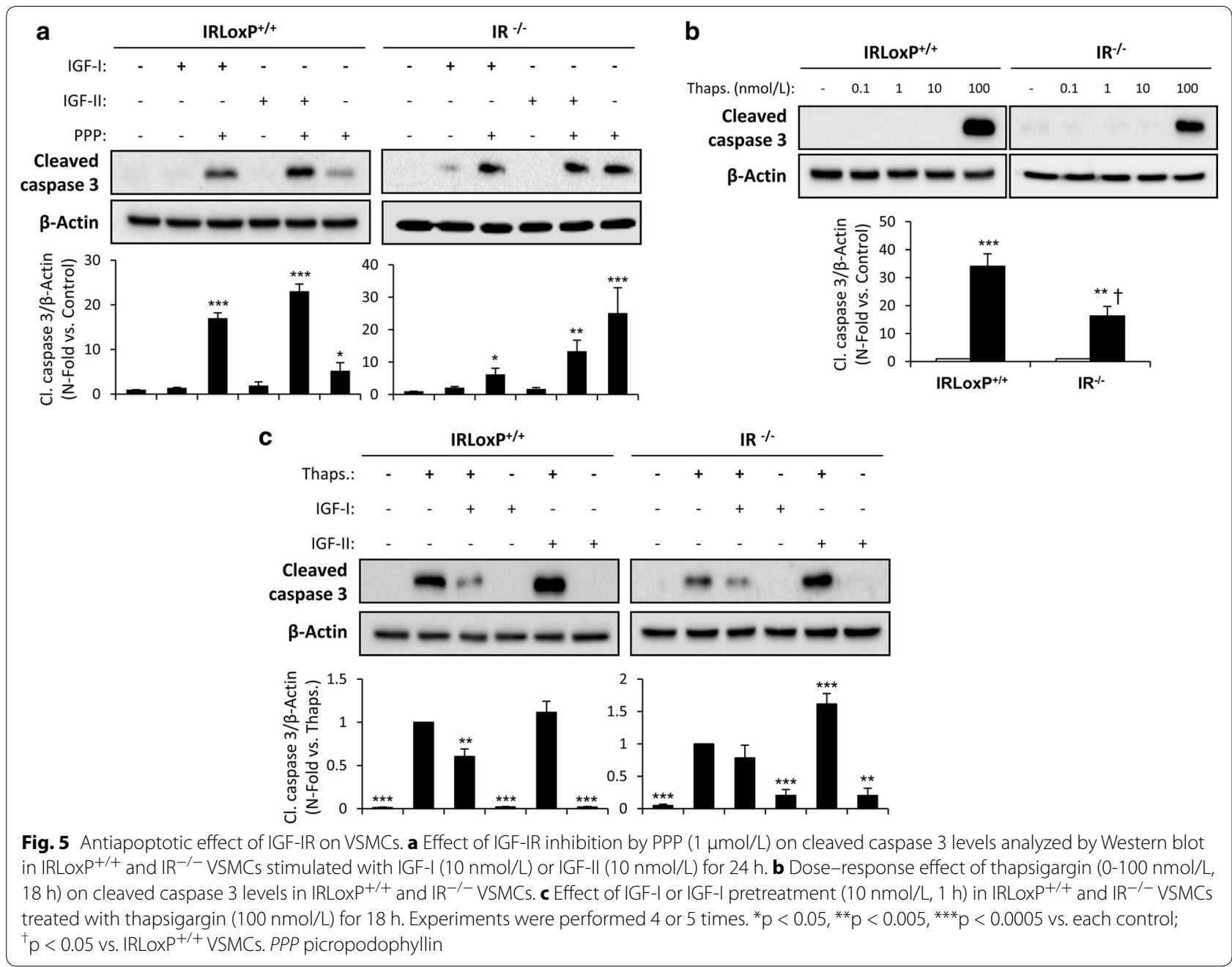

since it has been previously described IRs organized as holoreceptors favor insulin signaling [30]. There is ample clinical evidence that insulin resistance increases the risk for cardiovascular diseases even in the absence of hyperglycemia. Insulin resistance syndromes can promote both atherogenesis and advanced plaque progression, and the mechanisms likely involve both systemic factors, particularly dyslipidemia, hypertension, and a pro-inflammatory state, but also the effect of perturbed insulin signaling at the level of the intimal cells that participate in atherosclerosis, including endothelial cells, VSMCs, and macrophages [31]. In this sense, atherosclerotic plaques from diabetic subjects had larger necrotic cores, greater infiltration of inflammatory cells and increased apoptotic VSMCs and macrophages than nondiabetic subjects [32].

We also observed a decreased expression of IGF-IR in complicated as compared to non-complicated regions of human carotid plaques. IGF-I through IGF-IR prevents apoptosis, and promotes extracellular matrix formation, proliferation and migration of VSMCs. Furthermore, it has been described that IGF-I was less potent in inducing the survival of VSMCs from the endarterectomy specimens of symptomatic patients than those of asymptomatic subjects [33]. In this context, a decreased expression of IGF-I and IGF-IR in advanced atherosclerotic plaques has been involved in VSMCs apoptosis leading to plaque instability and rupture [18-20]. By contrast, IGF-IIR was increased in complicated human carotid plaques. There are evidences showing that in addition to lysosomal degradation of IGF-II [9], IGF-IIR may trigger intracellular signaling cascades involved in cell behavior regulation $[10,11]$. Deficiency of IGF-IIR in transgenic mice leads to ventricular hyperplasia in heart with an increased proliferation of fetal cardiomyocytes [34]. On the other hand, an increased cardiac expression of IGFII and IGF-IIR and cardiomyocyte apoptosis were found 


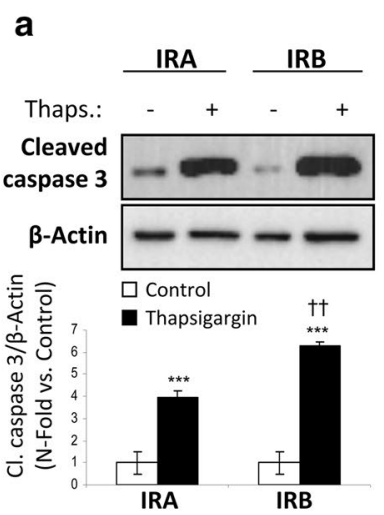

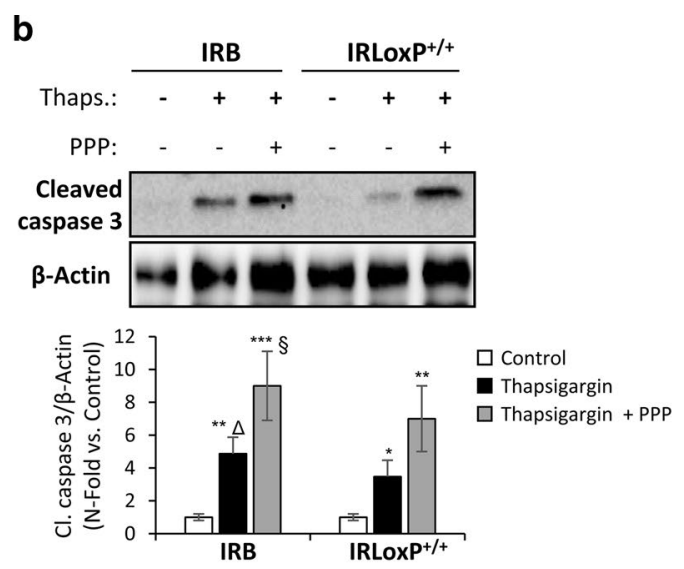

C

IRLoxP+/+ VSMCs
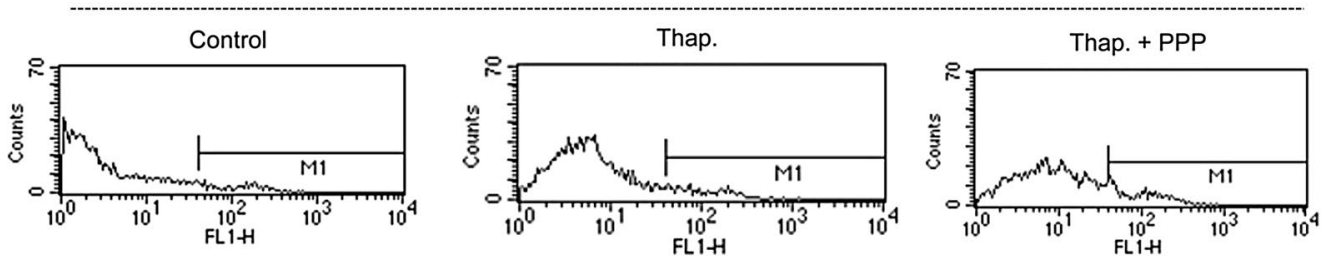

IRB VSMCS
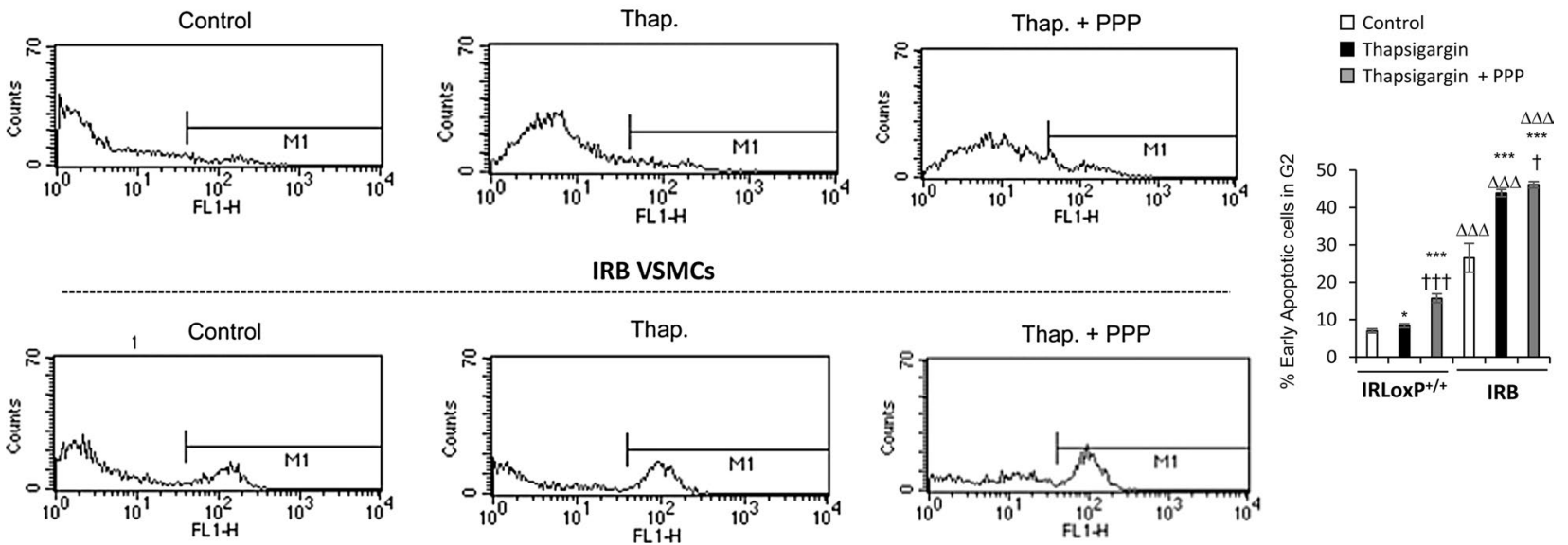

Fig. 6 Differential contribution of IR isoforms to VSMCs apoptosis. a Effect of thapsigargin ( $100 \mathrm{nmol} / \mathrm{L}, 18 \mathrm{~h}$ ) on cleaved caspase 3 levels analyzed by Western blot in IRA and IRB VSMCs. b Effect of IGF-IR inhibition by PPP ( $1 \mu \mathrm{mol} / \mathrm{L})$ on cleaved caspase 3 levels in IRB and IRLoxP ${ }^{+/+}$VSMCs treated with thapsigargin $(100 \mathrm{nmol} / \mathrm{L})$ for $18 \mathrm{~h}$. Experiments were performed 4 times. ${ }^{*} p<0.05,{ }^{* *} p<0.005,{ }^{* * *} p<0.0005$ vs. each control; ${ }^{+\dagger} p<0.005$ vs. IRA VSMCs; ${ }^{\S} \mathrm{p}<0.05$ vs. each thapsigargin; ${ }^{\Delta} p<0.05$ vs. IRLoxP ${ }^{+/+}$VSMCs. PPP: picropodophyllin. c \% of early apoptotic cells in G2. These cells were stained positively for Annexin V-FITC and negatively for propidium iodide. ${ }^{*} p<0.05$ vs. each control; ${ }^{* * *} p<0.001$ vs. each control; ${ }^{\dagger} p<0.05$ vs. each thapsigargin; ${ }^{+++} \mathrm{p}<0.001$ vs. each thapsigargin; ${ }^{\Delta \Delta \Delta} \mathrm{p}<0.001$ vs. each point of IRLox ${ }^{+/+}$VSMCs

in hypertensive rats with abdominal aorta ligation [35]. Other studies have supported the idea that IGF-II, acting through IGF-IIR, may promote the death of cardiac myocytes [36-38]. According to that data, the upregulation of IGF-IIR in atherosclerotic lesions could contribute to plaque instability by two potential mechanisms: reduced IGF-II bioavailability and thereby less effect on cell survival, or increased apoptosis of plaque-resident cells. Several studies have demonstrated the presence of apoptosis in human atherosclerotic plaques as the leading cause of loss of VSMCs [27, 39, 40]. Thus, unstable plaques from coronary atherectomy contained less apoptotic VSMCs and a reduced total cell number than stable plaques [41]. Consistently, we have described a decrease of VSMCs content in complicated human atherosclerotic plaques in relation to non-complicated regions. However, one of the limitations of this study is the small number of patients included, since it is difficult to obtain samples of the complicated and non-complicated regions of atherosclerotic plaques from the same patient. Therefore, in order to validate our results from human atherosclerotic plaques, additional studies including a greater number of patients need to be performed.

To assess whether the results obtained from human atherosclerotic plaques could be found in experimental atherosclerotic lesions, we used 24-week-old and 15-month-old BATIRKO; $\mathrm{ApoE}^{-/-}$mice that showed more advanced atherosclerotic plaques than $\mathrm{ApoE}^{-/-}$ mice. Nevertheless, although hyperlipidemic genetically manipulated models such as $\mathrm{ApoE}^{-1-}$ mice developed 


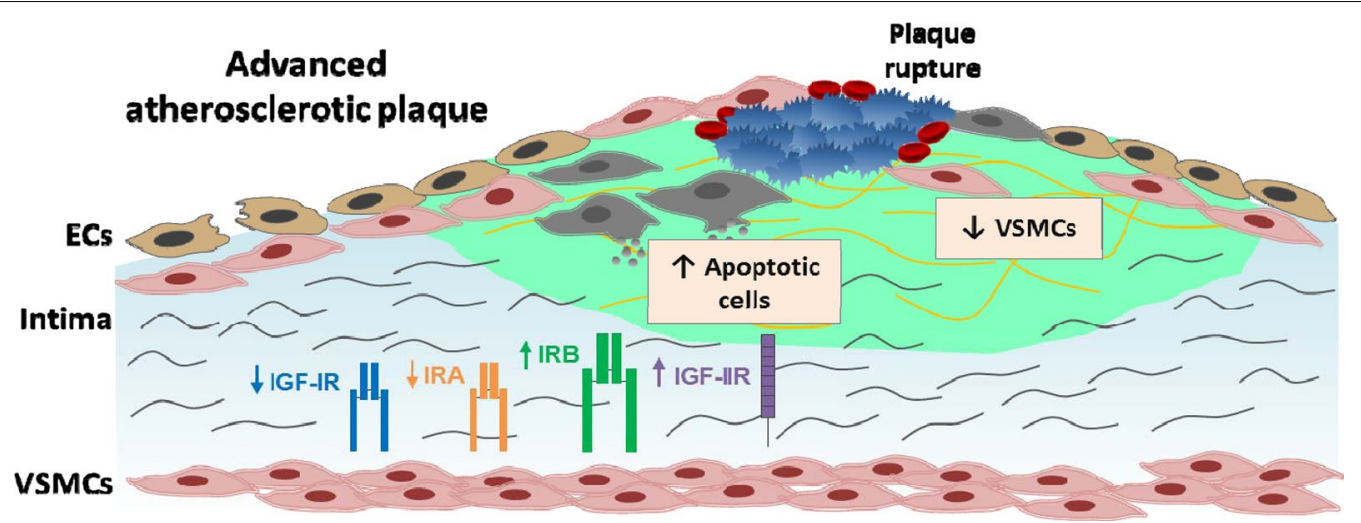

Fig. 7 Proposed scheme of an advanced atherosclerotic plaque showing the expression profiles of IR isoforms (IRA and IRB), IGF-IR and IGF-IIR. We found a decreased IRA/IRB ratio, increased IGF-IIR expression, and reduced IGF-IR expression, as well as lower VSMCs content in complicated versus non-complicated regions of human carotid plaques. In experimental models developing advanced atherosclerotic plaques, we also observed a reduced IRA/IRB ratio, a decrease of VSMCs content and an increase of apoptotic cell number. Finally, our in vitro results show that a decrease of IGFIR expression and the presence of IRB as the predominant IR isoform increase the apoptosis of VSMCs. Therefore, this scenario could contribute to a loss of VSMCs, promoting plaque instability and leading to a higher risk of plaque rupture with the outcome of vascular complications aggravation. ECs endothelial cells, VSMCs vascular smooth muscle cells

the entire spectrum of lesions similar to those of humans, their major limitation is the infrequency of plaque rupture and thrombosis, two common complications of human atherosclerosis [42]. Therefore, some, but not all, of the findings from complicated regions of human plaques were also observed in atherosclerosis plaques from BATIRKO; $\mathrm{ApoE}^{-1-}$ mice: decreased IRA/IRB ratio, increasing trend of IGF-IIR and reduced VSMC content with an increase of apoptotic cells. However, IGF-IR expression was increased in total area of aortic roots, but decreased in the media, in both $\mathrm{ApoE}^{-1-}$ and BATIRKO; $\mathrm{ApoE}^{-1-}$ mice vs. Control mice.

Our in vitro results indicate an antiapoptotic role of IGF-IR in VSMCs. The inhibition of IGF-IR by PPP induced apoptosis in IRLoxP $\mathrm{P}^{+/+}$and $\mathrm{IR}^{-/-}$VSMCs. We previously observed that the lack of IR in VSMCs led to an increased expression of IGF-IR [14], and this seems to be responsible for the lower thapsigargin-induced apoptosis that we found in $\mathrm{IR}^{-/-}$VSMCs as compared to IRLoxP ${ }^{+/+}$VSMCs. Moreover, IGF-I, but not IGF-II, exerts a protective effect on the thapsigargin-induced apoptosis of VSMCs. Consistently, VSMCs from human atherosclerotic plaques showed an intrinsic sensitivity to apoptosis caused in part by defective expression of IGF-IR, impaired IGF-I-mediated survival signaling and increased IGFBP secretion [19]. Oxidized LDL uptake has been proposed as a mechanism triggering apoptosis in VSMCs mediated by downregulation of IGF-IR [43]. Thus, overexpression of IGF-IR by using an adenovirus completely abrogated this effect on human VSMCs [44].
By contrast, IGF-II not only does not prevent VSMCs apoptosis, but also appears to enhance thapsigargininduced apoptosis in VSMCs lacking IR. This effect could be explained by IGF-II binding to IGF-IIR that, as mentioned above, has been reported to promote apoptosis in cardiomyocytes [33-36]. Finally, we found a differential contribution of IR isoforms to VSMCs apoptosis, since cells exclusively expressing IRB were more prone to thapsigargin-induced apoptosis than IRA or IRLoxP $\mathrm{P}^{+/+}$ VSMCs.

Overall, the data in this study advance our understanding of the pathophysiology of human carotid atherothrombosis and the potential role of IR isoforms and IGFs receptors in the stability of atherosclerotic plaques. Thus, our findings suggest that manipulation of the IGF-I autocrine/paracrine pathway may be a useful strategy to limit the loss of VSMCs that contribute to atherosclerotic plaque destabilization.

\section{Conclusions}

In conclusion, our results show for the first time a decreased IRA/IRB ratio and increased IGF-IIR expression as well as reduced IGF-IR expression in complicated versus non-complicated regions of human atherosclerotic plaques (Fig. 7). These events may contribute to an increased apoptosis and subsequent loss of VSMCs, promoting plaque instability and leading to a higher risk of plaque rupture with the outcome of vascular complications aggravation. 


\section{Additional files}

Additional file 1: Figure S1. Histological analysis of human carotid atherosclerotic plaques. Masson's trichrome stain of representative noncomplicated and complicated plaques of human carotid atherosclerosis. Different regions of the plaque are shown: M: media; F: fibrous region; A: atheroma; S: shoulder.

Additional file 2: Figure S2. Differential insulin signaling in complicated and non-complicated regions from atherosclerotic plaques. Western blot analysis of phosphorylation of Akt (A) and p42/44 MAPK (B) protein levels in supernatants from serial immunoprecipitations (IRB and IRA) of noncomplicated regions $(n=10)$ and their respective complicated regions $(n=10)$. CP: complicated region of atherosclerotic plaque; IP: immunoprecipitation; NCP: non-complicated region. ${ }^{*} p<0.05$ vs. NCP; ${ }^{* *} p<0.001$ vs. NCP.

Additional file 3: Figure S3. IR and IGF-IR expression in aorta from the 15-month-old model of experimental atherosclerosis. Representative photomicrographs and quantifications of immunohistochemistry against IR (A) or IGF-IR (B) in aortic roots from 15-month-old Control, ApoE ${ }^{-1-}$ and BATIRKO; ApoE ${ }^{-l-}$ mice. ${ }^{* *} \mathrm{p}<0.005,{ }^{* * *} \mathrm{p}<0.0005$ vs. Control mice; ${ }^{+\dagger} p<0.005$ vs. ApoE ${ }^{-1-}$ mice. C 15 m $(n=7) ; A E 15$ m $(n=6) ; B ; A E 15$ m $(n=6)$. AE: ApoE ${ }^{-1-}$, B;AE: BATIRKO; ApoE ${ }^{-/-} ; \mathrm{C}:$ Control.

Additional file 4: Figure S4. VSMC content and apoptosis in atherosclerotic plaques from the 15-month-old experimental model. Representative photomicrographs and quantification of immunofluorescence against a-SMA (A) and of immunohistochemistry against cleaved PARP (B) in aortic roots from 15-month-old Control, $\mathrm{ApoE}^{-1-}$ and BATIRKO; $\mathrm{ApoE}^{-/-}$mice. DAPI staining was performed to localize nuclei of cells presented in aortic roots (blue staining). ${ }^{*} p<0.05,{ }^{* * *} p<0.0005 \mathrm{vs}$. Control mice; ${ }^{\dagger} p<0.05$ vs. ApoE ${ }^{-/-}$mice. C $15 \mathrm{~m}(\mathrm{n}=7)$; AE $15 \mathrm{~m}(\mathrm{n}=6)$; B;AE 15 m ( $(n=6)$. AE: ApoE ${ }^{-/-}$, B;AE: BATIRKO; ApoE ${ }^{-1-} ;$ C: Control; DAPI: 4',6-diamidino-2-phenylindole; PARP: poly ADP ribose polymerase; a-SMA: a-smooth muscle actin.

Additional file 5: Figure S5. Antiapoptotic effect of IGF-IR and IGF-I on IRLoxP $\mathrm{P}^{+/+}$and IR ${ }^{-/-}$VSMCs. Analysis of dead cells by Annexin V-FITC and propidium iodide assays. (A) Representative images of $\%$ necrotic cells (UL), \% dead cells (UR), \% viable cells (LL) and \% early apoptotic cells (LR) in G1 Gate. FL1H (x-axis, Annexin V FITC); FL3H (y-axis, propidium iodide). Graphics of $\%$ of viable, \% of apoptotic cells (B), \% of necrotic cells, \% of dead cells and \% of early apoptotic cells (C). ${ }^{*} p<0.05$ vs. each Control; ${ }^{* *} p<0.001$ vs. each Control; ${ }^{* *} p<0.0001$ vs. each control; ${ }^{\dagger} p<0.05$ vs. each thapsigargin; ${ }^{\dagger+t} p<0.0001$ vs. each thapsigargin.

Additional file 6: Figure S6. Differential apoptotic effects of thapsigargin and IGF-IR inhibitor on IRLoxP $\mathrm{P}^{+/+}$and IRB VSMCs. Analysis of dead cells by Annexin V-FITC and propidium iodide assays. (A) Representative images of \% necrotic cells (UL), \% dead cells (UR), \% viable cells (LL) and $\%$ early apoptotic cells (LR) in G1 Gate. FL1H (x-axis, Annexin V FITC); FL3H (y-axis, propidium iodide). Graphics of $\%$ of viable, $\%$ of apoptotic cells (B), \% of necrotic cells, \% of dead cells and \% of early apoptotic cells (C). ${ }^{*} p<0.05$ vs. each control; ${ }^{* *} p<0.001$ vs. each control; ${ }^{* *} p<0.0001$ vs. each control; ${ }^{\dagger} p<0.05$ vs. each thapsigargin; ${ }^{\dagger+t} p<0.0001$ vs. each thapsigargin.

\section{Abbreviations}

a-SMA: a-smooth muscle actin; ApoE ${ }^{-/-}$: apolipoprotein E knockout; BATIRKO: brown adipose tissue-specific insulin receptor knockout; CP: complicated plaque; DAPI: 4',6-diamidino-2-phenylindole; IGF-l: insulin-like growth factor-l; IGF-II: insulin-like growth factor-II; IGF-IIR: insulin-like growth factor-II receptor; IGF-IR: insulin-like growth factor-I receptor; IGFs: insulin-like growth factors; IR: insulin receptor; IRA: insulin receptor $A$ isoform; IRB: insulin receptor $B$ isoform; IRS-1: insulin receptor substrate 1; NCP: non-complicated region of the plaque; PARP: poly ADP ribose polymerase; PPP: picropodophyllin; qRT-PCR: real-time quantitative PCR; VSMCs: vascular smooth muscle cells.

\section{Authors' contributions}

NB has participated in the acquisition of data, analysis and interpretation of data, and writing the manuscript. JLM- $V$ has participated in the acquisition of data in human samples and helped to draft the manuscript. CR-L has participated in the acquisition of data in in vitro experiments. OE has participated in the development of experimental model and helped to draft the manuscript. GG-G and SF have participated in the development of experimental model. GS and MLH have generated and provided IRB isoform antibody to performed immunoprecipitations of human plaques. JE helped to draft the manuscript. AG-H has participated in the acquisition of data, analysis and interpretation of data and in the design of study and its coordination as well as helped to draft the manuscript. MB leads as PI the projects that provided financial support for experiments. All authors read and approved the final manuscript.

\section{Author details}

${ }^{1}$ Biochemistry and Molecular Biology II Department, School of Pharmacy, Complutense University of Madrid, Plaza Ramón y Cajal s/n, 28040 Madrid, Spain. ${ }^{2}$ Health Research Institute of San Carlos Clinic Hospital (IdISSC), Madrid, Spain. ${ }^{3}$ CIBER of Diabetes and Associated Metabolic Diseases (CIBERDEM), Madrid, Spain. ${ }^{4}$ Vascular Research Lab, IIS-Fundación Jiménez Díaz-Autonoma University, Madrid, Spain. ${ }^{5}$ CIBER of Cardiovascular Diseases (CIBERCV), Madrid, Spain. ${ }^{6}$ Department of Medical and Surgical Sciences, University Magna Graecia of Catanzaro, Catanzaro, Italy.

\section{Acknowledgements}

We wish to thank Patricia Llamas Granada for technical assistance.

\section{Competing interests}

The authors declare that they have no competing interests.

\section{Availability of data and materials}

Data sharing not applicable to this article as no datasets were generated or analyzed during the current study.

\section{Consent for publication \\ Not applicable.}

\section{Ethics approval and consent to participate}

Atherosclerotic plaques from patients undergoing carotid endarterectomy were harvested with the authorization of the IIS-Fundación Jiménez Díaz's ethics committee according to the institutional and the Good Clinical Practice guidelines, which was performed in accordance with the Declaration of Helsinki. All participants gave written informed consent.

All animal experimentation was conducted according with accepted standards of human animal care, as approved by the institutional committee of Complutense University of Madrid. All animal procedures have been performed conform the guidelines from Directive 2010/63/EU of the European Parliament on the protection of animals used for scientific purposes or the $\mathrm{NIH}$ guidelines.

\section{Funding}

This work was supported by Grants SAF2011/22555, SAF2014-51795-R, SAF2016-80843-R from Ministerio de Ciencia e Innovación and (S2010/BMD2423) from Comunidad de Madrid to M. Benito and from CIBER de Diabetes y Enfermedades Metabólicas Asociadas (CIBERDEM), ISCIII, Spain.

\section{Publisher's Note}

Springer Nature remains neutral with regard to jurisdictional claims in published maps and institutional affiliations.

Received: 15 October 2017 Accepted: 12 February 2018

Published online: 20 February 2018

\section{References}

1. Libby P. Inflammation in atherosclerosis. Nature. 2002;420:868-74.

2. Libby $P$, Theroux P. Pathophysiology of coronary artery disease. Circulation. 2005;111:3481-8. 
3. Bennett MR, Sinha S, Owens GK. Vascular smooth muscle cells in atherosclerosis. Circ Res. 2016;1 18:692-702.

4. Ebina Y, Edery M, Ellis L, Standring D, Beaudoin J, Roth RA, Rutter WJ. Expression of a functional human insulin receptor from a cloned CDNA in Chinese hamster ovary cells. Proc Natl Acad Sci USA. 1985;82:8014-8.

5. Ullrich A, Gray A, Tam AW, Yang-Feng T, Tsubokawa M, Collins C, Henzel W, Le Bon T, Kathuria S, Chen E, Jacobs S, Francke U, Ramachandran J, Fujita-Yamaguchi Y. Insulin-like growth factor I receptor primary structure: comparison with insulin receptor suggests structural determinants that define functional specificity. EMBO J. 1986;5:2503-12.

6. Seino S, Bell GI. Alternative splicing of human insulin receptor messenger RNA. Biochem Biophys Res Commun. 1989;159:312-6.

7. Frasca F, Pandini G, Scalia P, Sciacca L, Mineo R, Costantino A, Goldfine ID, Belfiore A, Vigneri R. Insulin receptor isoform A, a newly recognized, highaffinity insulin-like growth factor II receptor in fetal and cancer cells. Mol Cell Biol. 1999;19:3278-88.

8. Belfiore A, Malaguarnera R, Vella V, Lawrence MC, Sciacca L, Frasca F, Morrione A, Vigneri R, Brown J, Jones EY, Forbes BE. Insulin receptor isoforms in physiology and disease: an updated view. Endocr Rev. 2017:38(5):379-431.

9. Interactions of IGF-II with the. IGF2R/cation-independent mannose6-phosphate receptor mechanism and biological outcomes. Vitam Horm. 2009;80:699-719.

10. McKinnon T, Chakraborty C, Gleeson LM, Chidiac P, Lala PK. Stimulation of human extravillous trophoblast migration by IGF-II is mediated by IGF type 2 receptor involving inhibitory $G$ protein(s) and phosphorylation of MAPK. J Clin Endocrinol Metab. 2001;86:3665-74.

11. Hawkes C, Jhamandas JH, Harris KH, Fu W, MacDonald RG, Kar S. Single transmembrane domain insulin-like growth factor-II/mannose-6-phosphate receptor regulates central cholinergic function by activating a G-protein-sensitive, protein kinase C-dependent pathway. J Neurosci. 2006;26:585-96.

12. Bayes-Genis A, Conover CA, Schwartz RS. The insulin-like growth factor axis: a review of atherosclerosis and restenosis. Circ Res. 2000;86:125-30.

13. Gómez-Hernández A, Escribano Ó, Perdomo L, Otero YF, García-Gómez G, Fernández S, Beneit N, Benito M. Implication of insulin receptor A isoform and IRA/IGF-IR hybrid receptors in the aortic vascular smooth muscle cell proliferation: role of TNF-a and IGF-II. Endocrinology. 2013;154:2352-64.

14. Beneit N, Fernández-García CE, Martín-Ventura JL, Perdomo L, Escribano Ó, Michel JB, García-Gómez G, Fernández S, Díaz-Castroverde S, Egido J, Gómez-Hernández A, Benito M. Expression of insulin receptor (IR) A and $B$ isoforms, IGF-IR, and IR/IGF-IR hybrid receptors in vascular smooth muscle cells and their role in cell migration in atherosclerosis. Cardiovasc Diabetol. 2016:15:161.

15. Davies MJ. The composition of coronary-artery plaques. N Engl J Med. 1997:336:1312-4.

16. Virmani R, Kolodgie FD, Burke AP, Farb A, Schwartz SM. Lessons from sudden coronary death: a comprehensive morphological classification scheme for atherosclerotic lesions. Arterioscler Thromb Vasc Biol. 2000;20:1262-75

17. Littlewood TD, Bennett MR. Apoptotic cell death in atherosclerosis. Curr Opin Lipidol. 2003;14:469-75.

18. Okura Y, Brink M, Zahid AA, Anwar A, Delafontaine P. Decreased expression of insulin-like growth factor-1 and apoptosis of vascular smooth muscle cells in human atherosclerotic plaque. J Mol Cell Cardiol. 2001;33:1777-89.

19. Patel VA, Zhang QJ, Siddle K, Soos MA, Goddard M, Weissberg PL, Bennett MR. Defect in insulin-like growth factor-1 survival mechanism in atherosclerotic plaque-derived vascular smooth muscle cells is mediated by reduced surface binding and signaling. Circ Res. 2001;88:895-902.

20. von der Thüsen $\mathrm{JH}$, Borensztajn $\mathrm{KS}$, Moimas $\mathrm{S}$, van Heiningen $\mathrm{S}$, Teeling $P$, van Berkel TJ, Biessen EA. IGF-1 has plaque-stabilizing effects in atherosclerosis by altering vascular smooth muscle cell phenotype. Am J Pathol. 2011:178:924-34

21. Gómez-Hernández A, Beneit N, Escribano Ó, Díaz-Castroverde S, García-Gómez G, Fernández S, Benito M. Severe brown fat lipoatrophy aggravates atherosclerotic process in male mice. Endocrinology. 2016:157:3517-28.

22. Durán MC, Martín-Ventura JL, Mohammed S, Barderas MG, Blanco-Colio LM, Mas S, Moral V, Ortega L, Tuñón J, Jensen ON, Vivanco F, Egido J.
Atorvastatin modulates the profile of proteins released by human atherosclerotic plaques. Eur J Pharmacol. 2007;562(1-2):119-29.

23. Escribano O, Guillén C, Nevado C, Gómez-Hernández A, Kahn CR, Benito M. Beta-Cell hyperplasia induced by hepatic insulin resistance: role of a liver-pancreas endocrine axis through insulin receptor A isoform. Diabetes. 2009;58:820-8.

24. Lytton J, Westlin M, Hanley MR. Thapsigargin inhibits the sarcoplasmic or endoplasmic reticulum Ca-ATPase family of calcium pumps. J Biol Chem. 1991:266:17067-71.

25. Fayad ZA, Fuster V. Clinical imaging of the high-risk or vulnerable atherosclerotic plaque. Circ Res. 2001;89:305-16.

26. Hamdan A, Assali A, Fuchs S, Battler A, Kornowski R. Imaging of vulnerable coronary artery plaques. Catheter Cardiovasc Interv. 2007;70:65-74.

27. Bennett MR, Evan Gl, Schwartz SM. Apoptosis of human vascular smooth muscle cells derived from normal vessels and coronary atherosclerotic plaques. J Clin Invest. 1995:95:2266-74.

28. Zaina S, Pettersson L, Ahrén B, Brånén L, Hassan AB, Lindholm M, Mattsson R, Thyberg J, Nilsson J. Insulin-like growth factor II plays a central role in atherosclerosis in a mouse model. J Biol Chem. 2002;277:4505-11.

29. Aguirre V, Uchida T, Yenush L, Davis R, White MF. The c-Jun NH(2)-terminal kinase promotes insulin resistance during association with insulin receptor substrate-1 and phosphorylation of Ser(307). J Biol Chem. 2000;275:9047-54.

30. Engberding N, San Martín A, Martin-Garrido A, Koga M, Pounkova L, Lyons $E$, Lassègue B, Griendling KK. Insulin-like growth factor-1 receptor expression masks the antiinflammatory and glucose uptake capacity of insulin in vascular smooth muscle cells. Arterioscler Thromb Vasc Biol. 2009;29:408-15.

31. Bornfeldt KE, Tabas I. Insulin resistance, hyperglycemia, and atherosclerosis. Cell Metab. 2011;14:575-85.

32. Burke AP, Kolodgie FD, Zieske A, Fowler DR, Weber DK, Varghese PJ, Farb A, Virmani R. Morphologic findings of coronary atherosclerotic plaques in diabetics: a postmortem study. Arterioscler Thromb Vasc Biol. 2004:24:1266-71.

33. Jia G, Cheng G, Agrawal DK. Differential effects of insulin-like growth factor-1 and atheroma-associated cytokines on cell proliferation and apoptosis in plaque smooth muscle cells of symptomatic and asymptomatic patients with carotid stenosis. Immunol Cell Biol. 2006;84:422-9.

34. Lau MM, Stewart CE, Liu Z, Bhatt H, Rotwein P, Stewart CL. Loss of the imprinted IGF2/cation-independent mannose 6-phosphate receptor results in fetal overgrowth and perinatal lethality. Genes Dev. 1994;8:2953-63.

35. Lee SD, Chu CH, Huang EJ, Lu MC, Liu JY, Liu CJ, Hsu HH, Lin JA, Kuo WW, Huang CY. Roles of insulin-like growth factor II in cardiomyoblast apoptosis and in hypertensive rat heart with abdominal aorta ligation. Am J Physiol Endocrinol Metab. 2006;291:E306-14.

36. Chen RJ, Wu HC, Chang MH, Lai CH, Tien YC, Hwang JM, Kuo WH, Tsai FJ, Tsai CH, Chen LM, Huang CY, Chu CH. Leu27IGF2 plays an opposite role to IGF1 to induce H9c2 cardiomyoblast cell apoptosis via Galphaq signaling. J Mol Endocrinol. 2009:43:221-30.

37. Chu CH, Tzang BS, Chen LM, Liu CJ, Tsai FJ, Tsai CH, Lin JA, Kuo WW, Bau DT, Yao CH, Huang CY. Activation of insulin-like growth factor II receptor induces mitochondrial-dependent apoptosis through G(alpha)q and downstream calcineurin signaling in myocardial cells. Endocrinology. 2009:150:2723-31.

38. Lin KH, Kuo CH, Kuo WW, Ho TJ, Pai P, Chen WK, Pan LF, Wang CC, Padma VV, Huang CY. NFIL3 suppresses hypoxia-induced apoptotic cell death by targeting the insulin-like growth factor 2 receptor. J Cell Biochem. 2015;116:1113-20.

39. Björkerud S, Björkerud B. Apoptosis is abundant in human atherosclerotic lesions, especially in inflammatory cells (macrophages and T cells), and may contribute to the accumulation of gruel and plaque instability. Am J Pathol. 1996;149:367-80.

40. Martín-Ventura JL, Blanco-Colio LM, Muñoz-García B, Gómez-Hernández A, Arribas A, Ortega L, Tuñón J, Egido J. NF-kappaB activation and Fas ligand overexpression in blood and plaques of patients with carotid atherosclerosis: potential implication in plaque instability. Stroke. 2004:35:458-63.

41. Bauriedel G, Hutter R, Welsch U, Bach R, Sievert H, Lüderitz B. Role of smooth muscle cell death in advanced coronary primary lesions: implications for plaque instability. Cardiovasc Res. 1999;41:480-8. 
42. Schwartz SM, Galis ZS, Rosenfeld ME, Falk E. Plaque rupture in humans and mice. Arterioscler Thromb Vasc Biol. 2007;27:705-13.

43. Higashi Y, Peng T, Du J, Sukhanov S, Li Y, Itabe H, Parthasarathy S, Delafontaine $P$. A redox-sensitive pathway mediates oxidized LDL-induced downregulation of insulin-like growth factor-1 receptor. J Lipid Res. 2005;46:1266-77.
44. Li Y, Higashi Y, Itabe H, Song YH, Du J, Delafontaine P. Insulin-like growth factor-1 receptor activation inhibits oxidized LDL-induced cytochrome C release and apoptosis via the phosphatidylinositol 3 kinase/Akt signaling pathway. Arterioscler Thromb Vasc Biol. 2003;23:2178-84.

\section{Submit your next manuscript to BioMed Central and we will help you at every step:}

- We accept pre-submission inquiries

- Our selector tool helps you to find the most relevant journal

- We provide round the clock customer support

- Convenient online submission

- Thorough peer review

- Inclusion in PubMed and all major indexing services

- Maximum visibility for your research

Submit your manuscript at

www.biomedcentral com/submit 